\title{
The opinion of patients with mental disorder about tobacco and its prohibition in psychiatric hospitalization*
}

\author{
OPINIÃO DOS PORTADORES DE TRANSTORNO MENTAL SOBRE O FUMO E SUA \\ PROIBIÇÃO NA INTERNAÇÃO PSIQUIÁTRICA
}

\author{
OPINIÓN DE LOS PORTADORES DE TRASTORNO MENTAL SOBRE EL TABACO Y SU \\ PROHIBICIÓN EN LA HOSPITALIZACIÓN PSIQUIÁTRICA
}

Renata Marques de Oliveira ${ }^{1}$, Antonia Regina Ferreira Furegato ${ }^{2}$

\begin{abstract}
Objective: To identify the opinion of patients with mental disorder about tobacco and its prohibition during psychiatric hospitalization. Method: An exploratory study with 96 patients smokers with mental disorders hospitalized in a psychiatric ward of a general hospital. The interviews were conducted individually, using an instrument designed for this study. The content from the interviews was recorded, transcribed and submitted to a thematic content analysis. Results: The patients with mental disorder were identified as perceiving smoking during the psychiatric hospitalization as a help to support the difficulties in socialization and in the lack of activities. The permission for smoking is seen as a signal of respect to their needs. The subjects mentioned to not accept the total smoking prohibition. Conclusion: Tobacco helps to face difficulties and conflicts in the psychiatric hospitalization. There is resistance regarding the possibility to totally withdraw the smoking permission during hospitalization.
\end{abstract}

\section{DESCRIPTORS}

Smoking

Mental disorders

Psychiatric Departament Hospital

Non- smoking areas

Psychiatric nursing

\section{RESUMO}

Objetivo: Identificar a opinião dos portadores de transtorno mental sobre o fumo e sua proibição durante a internação psiquiátrica. Método: Estudo exploratório com 96 portadores de transtorno mental, tabagistas, internados em enfermaria psiquiátrica de hospital geral. As entrevistas foram realizadas individualmente, utilizando-se o instrumento elaborado para este estudo. O conteúdo verbalizado nas entrevistas foi gravado, transcrito e submetido à análise de conteúdo temático. Resultados: Identificou-se que os portadores de transtorno mental veem o tabagismo na internação psiquiátrica como ajuda para suportar a dificuldade de convívio e a falta de atividades. A permissão do tabagismo é vista como sinal de respeito às suas necessidades. Os sujeitos relatam não aceitar a proibição total do tabagismo. Conclusão: $O$ tabagismo ajuda a enfrentar dificuldades e conflitos na internação psiquiátrica. Existe resistência quanto à possibilidade de retirar totalmente a permissão para fumar na internação.

\author{
DESCRITORES \\ Tabagismo \\ Transtornos mentais \\ Unidade Hospitalar de Psiquiatria \\ Áreas proibidas ao tabagismo \\ Enfermagem psiquiátrica
}

\begin{abstract}
RESUMEN
Objetivo: Identificar la opinión de los portadores de trastorno mental sobre el tabaco y su prohibición durante la hospitalización psiquiátrica. Método: Estudio exploratorio con 96 portadores de trastorno mental, tabaquistas, internados en el servicio psiquiátrico de un hospital general. Las entrevistas fueron realizadas individualmente utilizando un instrumento elaborado para este estudio. Se registró el contenido verbalizado en las entrevistas, que fueron transcritos y sometidos al análisis de contenido temático. Resultados: Los portadores de trastorno mental ven el tabaquismo en la hospitalización psiquiátrica como una ayuda para soportar la dificultad de la convivencia y la falta de actividades. La autorización del tabaquismo es visto como un signo de respeto a sus necesidades. Los sujetos refieren no aceptar la prohibición total del tabaquismo. Conclusión: El tabaquismo ayuda a enfrentar las dificultades y conflictos en la hospitalización psiquiátrica. Existe resistencia sobre la posibilidad de retirar por completo la autorización para fumar durante la hospitalización.
\end{abstract}

\section{DESCRIPTORES}

Tabaquismo

Trastornos mentales

Servicio de Psiquiatría en Hospital

Áreas prohibidas a fumadores

Enfermería psiquiátrica

\footnotetext{
* Extracted from the dissertation "Dependência de tabaco na esquizofrenia, sua relação com indicadores clínicos e o sentido para o usuário", Nursing School of Ribeirão Preto, Universidade de São Paulo, 2012. ${ }^{1}$ Master of Science by the Psychiatric Nursing Program, Nursing School of Ribeirão Preto, Universidade de São Paulo, Ribeirão Preto, SP, Brazil. renatamarques@ymail.com ${ }^{2}$ Full professor, Department of Psychiatric Nursing and Human Sciences, Nursing School of Ribeirão Preto, Universidade de São Paulo, Ribeirão Preto, SP, Brazil. furegato@eerp.usp.br
} 


\section{INTRODUCTION}

The frequency of smokers and the level of nicotine dependence within those with mental disorders are normally more elevated than in other population groups. The smoking damage in those individuals is severe, with compromises in the physical integrity and the disorder severity. It is suggested that the mental disorder influence the beginning and the maintenance of tobacco use due to the occurrence and integrity of different predictive factors social, environmental, psychological, neurobiological and genetic ${ }^{(1-4)}$.

Within the social and environmental factors, it is highlighted the psychiatric hospitalization services characteristics as the high number of smokers in those environments, the isolation caused by the hospitalization and the idle time. Those factors contributed to the process of transformation in the smoking habits in the institution $s^{(5-8)}$.

The smoking culture in the psychiatric services, demonstrated by the use of cigarettes as reward to incentive the patient with mental disorders to adhere to the therapeutic activities, to control the behavior and to facilitate the establishment of relationships with the team and other patients, seem to be decisive to use tobacco during the psychiatric hospitalization. However, the Brazilian Law 12.546, from 2011, through the smoking prohibition in shared closed places, impose a cultural model change to the Brazilian psychiatric services regarding the permission and the incentive to use cigarettes by patients and health professionals ${ }^{(5,7-9)}$.

To substitute a traditional culture, motivated by politic pressure, involve a process known as assimilation. When this process happen in great proportions in a forceful manner, it reflects negatively in those living it, because the abrupt assimilation of a new culture can lead to sociocultural identity loss and to resistance dealing with the new reality ${ }^{(10)}$. It reveals the need to investigate the smoking culture change in psychiatric services, because the way patients with mental disorders and professionals live the changing process influence its efficacy.

Recognizing the historical and cultural role of tobacco in psychiatric services, the present study intends to answer the following question: What do patients with mental disorder think about prohibiting them to smoke while hospitalized?

The objective was to identify the opinion of patients with mental disorder about tobacco and its restriction during the psychiatric hospitalization.

\section{METHOD}

The present study is a project aimed to study different aspects related to tobacco between patients with mental disorder and it is supported by the Brazilian National Council of Scientific and Technologic Development (CNPq).
The study presents the exploratory results of the qualitative data collection performed with the smoker patients with mental disorder, hospitalized in a psychiatric ward inside a general state hospital, from the São Paulo state inland. The ward has capacity for 18 beds with a $80 \%$ of occupation and a bed substitution interval of approximately 3 days.

Nowadays, tobacco is allowed inside the psychiatric ward only to patients who had the habit of smoking before being hospitalized, and the cigarette is offered in six different pre-determined times, sought by the patient to the nursing team, only if the patient or the family members bring the product from home and trust the nursing team to control it.

From the 433 patients hospitalized in the data collection period, 163 (37.6\%) were excluded: $23.3 \%$ were younger than 15 years old; $11 \%$ had a mental retardation diagnose; $21.5 \%$ did not present preservation of mental functions (behavior, cognitive functions, thinking process and perceptions); $19.6 \%$ refused to participate; and $24.5 \%$ were discharged from the hospital without previous planning, precluding the interview.

From the 270 selected subjects (initial sample), 174 (64.4\%) declared to be non-smokers; although we collected socio-demographic and clinical information from those subjects, they were not included in the present study. Ninety-six patients smoker patients with mental disorders, selected by a probabilistic method ( $95 \%$ of precision), answered the questions analyzed in this study.

The study was approved by the Committee of Ethics in Research (EERP/USP 1173/2010), it was authorized by the Clinical Hospital of Marilia for data collection and the Free Informed Consent (TCLE) was signed by the subjects.

The interviews were conducted individually, using the Instrument for Smokers Identification in Psychiatric ward of a general hospital - ISPW, elaborated for our study. The ITUP is composed by structured questions about socio-demographic data (gender, age, education, civil status, housing, occupation), as well as open questions to investigate the opinion of patients with mental disorders about smoking cigarettes and its restriction in the psychiatric hospitalization.

The verbal content from the interviews was recorded, transcribed and submitted to its theme content analy$\operatorname{sis}^{(11)}$ : 1) floating reading; 2 ) emphasis of meaning nucleus; 3) theme identification; and 4) category definition. The results discussion were based on the scientific literature.

\section{RESULTS}

The results are presented in two topics: A) Subject's Characteristics and B) Thematic analysis of content.

\section{A) Subject's Characteristics}

The sample was predominantly composed by women (61.5\%), mean age 38.2 years (15 to 69 years). Most of 
subjects had completed only middle school (53.1\%), lived in urban area $(91.7 \%)$ and declared to have an occupation (61.5\%). The highest proportion was single subjects $(43.8 \%)$ and subjects that used to live without a partner, but with other people (50\%).

The main clinical information of subjects are presented in Table 1.

Table 1 - Clinical characteristics of 96 Smokers with mental disorders hospitalized in a psychiatric ward - Marília SP, 2010 to 2012

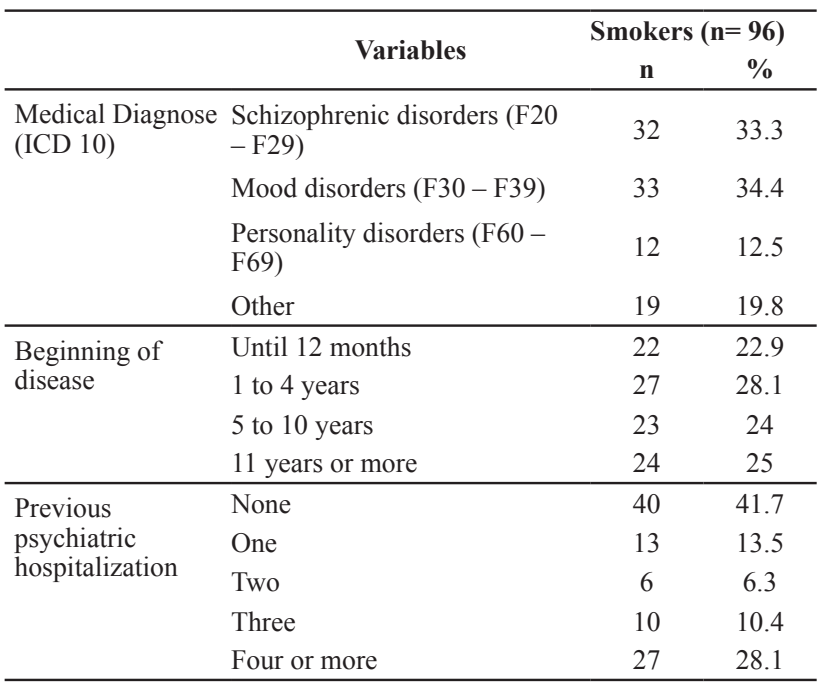

\section{B) Thematic analysis of content}

Two thematic categories were identified: 1) Smoking during hospitalization: influence of myths about nicotine abstinence in patients with mental disorder; and 2) Opinion about tobacco and its restrictions in the psychiatric hospitalization.

\section{1) Smoking during hospitalization: influence of myths about} nicotine abstinence in patients with mental disorder

The permission to smoke during hospitalization surprised the subjects, who asked about the reasons, allowing the identification of the main myths about tobacco removal in patients with mental disorders, as the stress and aggressiveness increase.

I thought it was a little strange they let us smoke [in hospitalization]. Now I ask you: why do they let us smoke? Is it because the patients are depressed? It is because if they do not [smoke], they will be more nervous, stressed? Is that it? (S 5).

Maybe, if staying without smoking, will end up beating someone (S 36).

I think for the professional [the cigarette] is safety (...) The psychiatric cases have aggressiveness, depression, it is something more severe (S 81).

Subjects believe that nicotine abstinence can aggravate the mental disorder presentation.

I think it's normal to let [smoke during hospitalization], because if it's a person who smokes for a long time, if he gets hospitalized here, he will already feel bad; now, if you take his cigarette, he might freak out (S 11).

If you take [the cigarette] from a person that is psychologically dependent, he will get worse. (...) It is the same thing as taking the sweet milk from a kid. [lf you take the cigarette] the patients will get disappointed and fall on the ground (S 15).

We are already nervous, we came here with depression, if you take away the cigarette we get worse (S 17).

The permission to smoke during the psychiatric hospitalization, surrounded by myths as the increase in stress and aggressiveness and aggravation of mental disorder, brings out the feeling of difference and the perception that they depend on cigarettes more than other people.

I think we can smoke here because we have some little screws in the wrong place (S 12).

As it is a psychiatric ward that affects our minds too much, I think they let the cigarette free for this reason, because they know we depend on it (S 19).

This way we can think the institution differs the psychiatric and non-psychiatric patients. Because here [psychiatric ward] it is allowed to smoke and in the others [clinical wards] it is not? (S 80).

2) Opinion about tobacco and its restrictions in the psychiatric hospitalization

The subjects recognize the cigarette role to help supporting some hospitalization situations, as the difficulty to socialize whit other patients and lack of activities.

Here there are fights, arguments, one day the person wakes up fine, and another, disturbed. There is variation, they vary, say nonsense things, then I feel apprehensive and I feel like smoking. I control myself, then I start to shake, those addiction crisis, you know? (S 8).

I don't know if it is because here we are stuck, there is no activity; so, you end up feeling like smoking. (...) In my other hospitalization, there was a patient who quit smoking a long time ago. He came here, saw everybody smoking and also picked up a cigarette: 'I see everybody smoking, I can't do anything, so l'll smoke (S 9).

When you smoke, time passes faster (S 10).

When I see something wrong I get angry and I crave more for cigarettes. (...) I feel bad to see some things [physical restrain], it affects me (S 13).

Here, it [cigarette] decreases anxiety. Here, we are within psychotic people, right? It is not easy to socialize here (S 15).

Here you have all day for nothing. (...) Here there is too much free time and with free time we feel anxiety, the need to do something, then they crave for cigarettes. (...) The cigarette works here as a scape: 'Waw! It's time! I can get a cigarette to smoke! (S 29).

Without cigarette here, my hospitalization would be tedious (S 65). 
For the subjects, to allow smoking during hospitalization is signal of respect to its needs.

I don't think it's a bad idea [to allow smoking during hospitalization] because the person comes with an addiction from outside, right? The person already comes with a problem; if the person is here and there is no cigarette, how would the person feel? (...) It must have cigarette (S 2).

I think it is healthy [to allow smoking during hospitalization] for the person so they don't feel their rights suddenly taken away. (...) It is important for the person to be itself. Cigarette is a way to for the person to feel minimally what they used to be before ( $\mathrm{S} 48$ ).

People imagine how would be the hospitalization if the allowance to smoke were totally taken away, showing resistance regarding the possibility to implement this measure.

If I'd stayed without my cigarette, in twenty days that I'm here, I think I would freak out. (...) If I couldn't smoke, I think I would have left, you know? (S 5).

If I couldn't smoke it would be hopeless, nerve-racking really, because you have this addiction, right? (S 13).

Have you ever thought of a smoker not having any cigarette to smoke? I would get angry, would get aggressive. (...) If you prohibit a cigarette here, I will not follow the right treatment. (...) I don't fight inside here because I have cigarettes (S 28).

Have you ever thought if they didn't allow anything? I would have broken my head against the wall. I am favorable [to be allowed to smoke during hospitalization] because cutting [the cigarette] hurts radically. (...) They know cutting radically cigarettes makes us freak-out (S 30).

\section{DISCUSSION}

This study shows tobacco helping patients with mental disorder to face difficulties generated by psychiatric hospitalization. Subjects look for cigarettes during hospitalization to face two principal difficulties: the lack of activities in the ward (idleness) and the difficulty to socialize with other patients, situations which generate stress and anxiety.

A longitudinal study of patients with mental disorder in Switzerland compared the perception about tobacco in two distinct moments, before and after the implementation of a partial restriction measure. The study showed that half of patients believe that psychiatric hospitalization influences smoking and this perception was not changed after the restriction implementation. For the patients with mental disorder, the principal reasons to incentive them to smoke during hospitalization was the lack of activities (39\%) and nervousness/stress (37\%) arisen from experiences in the ward $^{(6)}$.

The lack of activities in the psychiatric wards contributed for the hospitalization to be known as a moment of deprivation, with rules and routines which make the patient with mental disorder to feel as the control for their actions have been taken away. In this direction, the subjects of this study recognize the permission to tobacco during hospitalization as a way to have their rights guaranteed and their needs respected, agreeing with the author's thoughts ${ }^{(12)}$ when they affirm about the tobacco restriction having ethical implications, because it is taken away their right to choose what they consider better for themselves.

Besides the hospitalization being a moment of restrictions, it can be experienced as an impacting moment for those people without hospitalization history in those services. To experience situations as psychotic episode and physical restrain is painful for some patients that have an anguish relief generated by those experiences with a cigarette. However, the difficulty generated by hospitalization and the tobacco role to help them overcome those, cannot be an excuse to keep using tobacco in psychiatric wards.

Changes are needed in the attitude of professionals, assuming their role and responsibility in helping the patients to face the hospitalization conflicts. It is time for the professionals to call the responsibility to themselves, and the principal care tool should be therapeutic resources revealed by their professional practice, and not the cigarette, as it has being used for many years in this service.

The cigarette is recognized as the first option to help patients to deal with hospitalization conflicts, because the nicotine effects as self-medication is immediate for anguish, anxiety and stress symptoms. This present practice nowadays accompanied many nursing generations, recognizing the change of this course of action as a rupture with a historical and cultural heritage of this services.

To rupture with the tobacco culture in psychiatric institutions, the conceptions and the nursing role need to be revised, as well as the possibilities to establish an efficient therapeutic relationship with patients. Through the therapeutic relationship and the establishment of trust, the nurse can help the patient with mental disorder to understand the conflicts experienced during hospitalization and to find resources to face them. The possibilities brought to the psychiatric patient by the therapeutic relationship are long lasting and possible to apply in other situations of conflict in life, while the cigarette is temporary ${ }^{(13-15)}$.

In the present study, the existing difference between the tobacco restriction to psychiatric patients and the clinical patients was questioned, once in the studied general hospital there is permission to tobacco only in the psychiatric ward. It is believed that to not intervene in the tobacco for patients with mental disorder is to reinforce the feeling of difference between them and the other patients; it feels like they were left behind ${ }^{(8)}$.

Besides the inequality feeling, to allow tobacco only in the psychiatric ward means sending the message to patients with mental disorder that professionals do not believe in 
their ability and motivation to quit smoking. To feel discredited can make the psychiatric patient to attribute a higher value to tobacco comparing to its real value, making them feel more dependent and incapable to leave it.

Beyond the incentive to smoke, caused by the lack of activities in the psychiatric hospitalization, smokers from an Australian study reported to feel motivated to smoke by the smokers professionals. The moments when they smoke accompanied by those professionals are described as the most pleasurable during hospitalization, because they feel accepted ${ }^{(16)}$.

An Irish research with 300 nurses from different specialties from a university hospital found almost half of the professionals working in the psychiatric ward, were smokers. Within the smoker nurses, there were those who believed less in tobacco harms and support less their restriction during hospitalization ${ }^{(17)}$. The influence from those professionals upon the patients reinforces the tobacco culture in psychiatric services, suggesting a need for studies investigating tobacco in the psychiatric institutions from the professionals' perspective.

One of the strengthening points to continue the tobacco culture in psychiatric wards is related to the belief of aggressiveness in patients with mental disorder when tobacco is taken away from them. This is one of the most recognized myths by the subjects in the present study who revealed the cigarette offer as a help to professionals to feel safe during the provided care. This perception is coherent with a research which showed the violence risk as one of the main worries within nursing professionals during hospitalization ${ }^{(18)}$.

The myth of aggressiveness increase was contested by a Canadian study that investigated 90 patient charts when those were hospitalized and it was completely prohibited to smoke in the psychiatric ward and 90 patient charts when those were hospitalized after one room was open for smokers. The comparison of charts from 180 patients did not reveal a significant decrease in the disruptive behavior (verbal aggressions, aggressions directed to objects, aggression against people, need for physical restrain) from patients with mental disorder after allowance to smoke in the ward ${ }^{(19)}$.

Another recognized belief from subjects of the present study was regarding the aggravation of the mental disorder with a cigarette limitation, as they believed tobacco has a self-medication effect. This myth is contested when we consider that within the patients with mental disorder, the smokers are the most severe ones, because tobacco interfere in the drug therapy and in the production of some symptoms, predisposing the them to trigger outbreaks ${ }^{(2-3)}$.

A research conducted with schizophrenics in a psychiatric hospital in Israel help to demystify the belief of severity increase with tobacco withdraw; after submitting subjects to reduce the quantity of cigarettes, a significant improvement in psychiatric symptoms was observed ${ }^{(20)}$.

When questioned about the possibility of totally withdrawing the allowance to smoke during psychiatric hospitalization, the patients with mental disorder were resistant, as they do not believe to be able to face the hospitalization without cigarettes as a support.

The resistance regarding the possibility to implement total restriction to tobacco is found in a Swiss study that compared the opinion of patients with mental disorder with the nursing team about the total tobacco prohibition in two moments, before and after its implementation. The study found before the prohibition, $87 \%$ of subjects declared to be against this measure; however, after its implantation, its acceptance seemed to have improved, with 55\% of subjects considering it too severe ${ }^{(21-22)}$.

A Canadian study with 816 psychiatric services professionals showed the percentage of professionals who declared to be in favor of tobacco restriction in the services increased with time, after its implantation. From the 430 investigated professionals, after two to three months of tobacco prohibition, $72.6 \%$ declared to be totally supportive to the prohibition, while, from the 386 professionals investigated after two years of the prohibition, $78.2 \%$ declared to be in favor ${ }^{(23)}$.

The initial resistance presented from the patients with mental disorder and professionals in relation to the tobacco withdraw in psychiatric services cannot fade this measure to failure. The professionals need to be prepared to work with tobacco prohibition in psychiatric institutions, letting the tobacco culture to give space to a culture which prioritizes health promotion, respect, dialogue and the potentials of the patient with mental disorders.

Study limitations: 1- the opinion of former smokers and non-smokers was not investigated, although they are exposed to tobacco during hospitalization; 2- high frequency of refusal.

\section{CONCLUSION}

Tobacco is still considered a support to the patient with mental disorder during psychiatric hospitalization. The prevalent opinion of tobacco as a support to face difficulties and hospitalization conflicts can influence the decision about smoking withdraw and to increase resistance regarding the possibility to implement total restriction in those services.

This study brings important contribution to nursing, demystifying some beliefs about cigarette smoking prohibition during psychiatric hospitalization. The knowledge produced prepares the nurse to assume with more responsibility his role during the hospitalization, helping patients to face their conflicts and to surpass the nicotine abstinence difficulty. 


\section{REFERENCES}

1. Lawrence D, Mitrou F, Zubrick SR. Smoking and mental illness: results from populations surveys in Australia and the United States. BMC Public Health [Internet]. 2009 [cited 2013 Jan 22]; 9:285. Available from: http://www.ncbi.nlm.nih.gov/ pmc/articles/PMC2734850/

2. Winterer G. Why do patients with schizophrenia smoke? Curr Opin Psychiatry. 2010;23(2):112-9.

3. Aubin HJ, Rollema H, Svensson TH, Winterer G. Smoking, quitting, and psychiatry disease: a review. Neurosci Biobehav Rev. 2012;36(1):271-84.

4. Oliveira RM, Furegato ARF. Esquizofrenia y dependencia del tabaco: una revisión integradora. Rev Enferm Global. 2012;11(1):381-402.

5. Dwyer T, Bradshaw J, Happell B. Comparison of mental health nurses'attitudes towards smoking and smoking behavior. Int J Ment Health Nurs. 2009;18(6):424-33.

6. Keizer I, Descloux V, Eytan A. Variations in smoking after admission to psychiatric inpatients units and impact of a partial smoking ban on smoking and on smoking-related perceptions. Int J Soc Psychiatry. 2009;55(2):109-23.

7. Solway E. Windows of opportunity for culture change around tobacco use in mental health settings. J Am Psychiatr Nurses Assoc. 2009;15(1):41-9.

8. Ratschen E, Britton J, Mcneill A. The smoking culture in psychiatry: time for change. Br J Psychiatry. 2011;198(1):6-7

9. Brasil. Lei n. 12.546, de 14 de dezembro de 2011. Art. 49. Altera os Arts. 2ㅇ e 3ㅇ da Lei n. 9.294, de 15 de julho de 1996 [Internet]. Brasília; 2011 [citado 2013 jan. 22]. Disponível em: http://www. receita.fazenda.gov.br/Legislacao/leis/2011/lei12546.htm

10. Tseng WS. Culture change and coping. In: Tseng WS. Handbook of cultural psychiatry. Toronto: Academic Press; 2001. p. 683-694.

11. Bardin, L. Análise de conteúdo. Lisboa: Edições 70; 2011.

12. Shattell MM, Andes M. Smoking bans in acute care psychiatric settings: a Machiavellian smoke screen? Issues Ment Health Nurs. 2008;29(2):201-3.

13. Freeth R. Humanising psychiatry and mental health care. New York: Radcliffe; 2007.
14. Furegato ARF, Scatena MCM. Bases do relacionamento interpessoal em enfermagem. In: Leite MMJ. PROEFN - Programa de Atualização em Enfermagem Saúde do Adulto. Porto Alegre: Artmed; 2009.

15. Moreira LHO, Loyola CMD. Involuntary commitment: implication for psychiatric nursing practice. Rev Esc Enferm USP [Internet]. 2011 [cited 2013 Jan 22];45(3):692-9. Available from: http://www.scielo.br/pdf/reeusp/v45n3/en_ v45n3a21.pdf

16. Lawn SJ, Pols RG, Barber JG. Smoking and quitting: a qualitative study with community -living psychiatric clients. Soc Sci Med. 2002;54(1):93-104.

17. O'Donovan G. Smoking prevalence among qualified nurses in the Republic of Ireland and their role in smoking cessation. Int Nurs Rev. 2009;56(2):230-6.

18. Oliveira RM, Siqueira Júnior AC, Furegato ARF. Cuidado de enfermagem implementado em internações psiquiátricas. Rev Enferm UFPE On Line [Internet]. 2012 [citado 2013 jan. 22];6(7):1599-607. Disponível em: file:///C:/Documents\%20and\%20Settings/2509501/Meus\%20documentos/Downloads/2936-26289-1-PB.pdf

19. Crockford D, Kerfoot K, Currie S. The impact of opening a smoking room on psychiatric inpatient behavior following implementation of a hospital -wide smoking ban. J Am Psychiatr Nurses Assoc. 2009;15(6):393-400.

20. Gelkopf M, Noam S, Rudinski D, Lerner A, Behrbalk P, Bleich $A$, et al. Nonmedication smoking reduction program for inpatients with chronic schizophrenia: a randomized control design study. J Nerv Ment Dis. 2012;200(2):142-6.

21. Etter M, Etter JF. Acceptability and impact of a partial smoking ban in a psychiatric hospital. Prev Med. 2007;44(1):64-9.

22. Etter M, Khan AN, Etter JF. Acceptability and impact of a partial smoking ban followed by a total smoking ban in a psychiatric hospital. Prev Med. 2008;46(6):572-8.

23. Voci S, Bondy S, Zawertailo L, Walker L, George TP, Selby P. Impact of smoke-free policy in a large psychiatric hospital on staff attitudes and patient behavior. Gen Hosp Psychiatry. 2010;32(6):623-30.

\section{Acknowledgements}

To the Brazilian National Council of Scientific and Technologic Development (CNPq) for funding this study Edital MCT/CNPQ no 70/2009 (Process no 145781/2010-0). To the Clinical Hospital of Marília for allowing the data collection.

\section{Conflicts of interest}

The authors declare as not having any conflicts of interest. 